\title{
PEMENUHAN HAK ATAS BANTUAN HUKUM DALAM PERKARA PIDANA BAGI MASYARAKAT MISKIN KOTA SEMARANG
}

\author{
Pratiwa Eka Chundhamani \\ Fakultas Hukum, Universitas Stikubank (UNISBANK) Semarang \\ e-mail : pratiwaekachundhamani@gmail.com
}

\begin{abstract}
ABSTRAK
Penyelenggaraan pemberian bantuan hukum kepada masyarakat miskin merupakan upaya untuk memenuhi dan sekaligus sebagai implementasi negara hukum yang mengakui dan melindungi serta menjamin hak asasi warga negara akan kebutuhan akses terhadap keadilan dan kesamaan di hadapan hukum. Tujuan penulisan skripsi ini adalah untuk menjelaskan mekanisme pemberian bantuan hukum pidana bagi masyarakat miskin di Kota Semarang, pemenuhan hak atas bantuan hukum pidana bagi masyarakat miskin, dan faktor penghambat pemenuhan hak atas bantuan hukum pidana bagi masyarakat miskin Kota Semarang. Metode pendekatan yang digunakan adalah yuridis normatif, spesifikasi penelitian deskriptif analitis. Sumber data yang digunakan adalah data data sekunder. Metode pengumpulan data yang digunakan adalah studi kepustakaan. Penelitian ini disajikan dalam bentuk laporan yang diuraikan secara induksi melalui analisis data yang bersifat kualitatif. Hasil penelitian menunjukkan bahwa mekanisme pemberian bantuan hukum pidana bagi masyarakat miskin di Kota Semarang telah sesuai dengan ketentuan UndangUndang Nomor 11 Tahun 2016 tentang Bantuan Hukum, Peraturan Daerah Kota Semarang Nomor 1 Tahun 2016 tentang Penyelenggaraan Bantuan Hukum serta Peraturan Walikota Semarang Nomor 131 Tahun 2016 tentang Petunjuk Pelaksanaan Peraturan Daerah Kota Semarang Nomor 1 Tahun 2016 tentang Penyelenggaraan Bantuan Hukum. Pemenuhan hak atas bantuan hukum pidana bagi masyarakat kota Semarang sejauh ini pemenuhan hak bantuan hukum dalam perkara pidana terhadap masyarakat miskin Kota belum maksimal karena belum bisa dirasakan oleh seluruh lapisan masyarakat khususnya masyarakat miskin yang belum mengetahui akan adanya bantuan hukum gratis, selain itu juga terkendala dengan keterbatasan anggaran biaya. Faktor penghambat pemenuhan hak atas bantuan hukum pidana bagi masyarakat Kota Semarang adalah faktor pendanaan, faktor penegak hukum dan faktor masyarakat.
\end{abstract}

Kata kunci : bantuan hukum, perkara pidana, masyarakat miskin 


\begin{abstract}
The provision of legal aid to the poor is an effort to fulfill and simultaneously implement a rule of law that recognizes and protects and guarantees the human rights of citizens regarding the need for access to justice and equality before the law. The purpose of writing this thesis is to explain the mechanism for providing criminal legal aid for the poor in Semarang City, the fulfillment of the right to criminal legal aid for the poor, and the inhibiting factors for fulfilling the right to criminal legal aid for the poor in Semarang City. The approach method used is juridical normative, descriptive analytical research specifications. The data source used is secondary data. The data collection method used is literature study. This research is presented in the form of a report which is described induction through qualitative data analysis. The results showed that the mechanism of providing criminal legal assistance to the poor in Semarang City was in accordance with the provisions of Law Number 11 of 2016 concerning Legal Aid, Semarang City Regulation Number 1 of 2016 concerning Implementation of Legal Aid and Regulation of the Mayor of Semarang Number 131 of 2016 concerning Guidelines for the Implementation of Semarang City Regional Regulation Number 1 of 2016 concerning the Implementation of Legal Aid. The fulfillment of the right to criminal legal aid for the people of Semarang city so far the fulfillment of the right to legal aid in criminal cases against the urban poor has not been maximized because it has not been felt by all levels of society, especially the poor who do not know about the existence of free legal assistance, besides that it is also constrained by budget constraints. The factors inhibiting the fulfillment of the right to criminal legal aid for the people of Semarang City are funding factors, law enforcement factors and community factors.
\end{abstract}

\title{
Keywords : legal aid, criminal cases, poor people
}

\section{Pendahuluan}

Bantuan hukum adalah hak konstitusional setiap warga. Lahirnya Undang-Undang Nomor 16 tahun 2011 tentang Bantuan Hukum seharusnya menjadi wujud nyata tanggung jawab negara terhadap Hak Atas Bantuan Hukum sebagai akses keadilan bagi seluruh masyarakat Indonesia sebagaimana diamanahkan oleh UUD 1945, UU Nomor 39 tahun 1999 tentang Hak Asasi Manusia (HAM), Kitab Undang-Undang Hukum Acara Pidana (KUHAP), Deklarasi Universal Hak Asasi Manusia, pasal 14(3) (d) Kovenan Internasional tentang HakHak Sipil dan Politik (International

Covenant on Civiland Political Rights) yang telah disahkan melalui UndangUndang Nomor 12 Tahun 2005, juga ada pemberian jaminan bagi setiap orang untuk mendapatkan bantuan hukum dan pelayanan dari Advokat ( $a$ right to have a legal counsel) yang berkualitas bagi masyarakat miskin.

$$
\text { Bantuan hukum menurut }
$$

ketentuan Pasal 1 Undang-Undang Nomor 16 Tahun 2011 tentang Bantuan Hukum adalah jasa hukum yang diberikan oleh pemberi bantuan hukum secara cuma-cuma kepada penerima bantuan hukum. Penerima bantuan hukum adalah orang atau 
kelompok orang miskin, sedangkan pemberi bantuan hukum adalah lembaga bantuan hukum atau organisasi kemasyarakatan yang memberi layanan bantuan hukum berdasarkan Undang-Undang.

Provinsi Jawa Tengah sebagai salah satu daerah otonom di Indonesia memiliki jumlah penduduk miskin yang cekup besar. Pada Tahun 2010 jumlah penduduk miskin di Jawa Tengah mencapai 16,56 persen dari total jumlah penduduk sebesar 32 juta. Sedangkan pada Tahun 2011 persentase kemiskinan di Jawa Tengah mencapai 16,21 persen dan pada Tahun 2012 mencapai 14,98 persen. Kebijakan untuk pemberian bantuan hukum kepada masyarakat miskin belum mampu sepenuhnya terbangun secara efektif mengingat belum adanya payung hukum yang kuat, sehingga pemerintah provinsi Jawa Tengah selanjutnya mengesahkan Perda Jateng Nomor 7 Tahun 2014 tentang Bantuan Hukum Untuk Masyarakat Miskin. ${ }^{1}$

Di Kota Semarang banyak kasus hukum yang dialami para warga miskin, sehingga Pemerintah Kota Semarang membuat regulasi agar mereka yang terkena kasus hukum bisa dibantu melalui pengacara yang ditunjuk oleh Pemrintah Kota Semarang. ${ }^{2} \quad$ Kebijakan Pemerintah Kota Semarang membuat Perda Nomor 1 Tahun 2016 tentang Pemberian Bantuan Hukum Untuk Orang Miskin ini merupakan amanat Undang-Undang Nomor 16 Tahun 2011. Dalam undang-

${ }^{1}$ Konsideran Peraturan Daerah Provinsi Jawa Tengah Nomor 7 Tahun 2014 tentang Bantuan Hukum untuk Masyarakat Miskin.

2 Pemkot Semarang Hanya Bisa sekali Beri Bantuan Hukum kepada Warga Miskin, (http://jateng.tribunnews.com, diakses 20 September 2018). undang tersebut mewajibkan Pemda memberikan bantuan hukum untuk warga miskin.

Pemerintah Kota Semarang telah menganggarkan 150 bantuan hukum untuk orang miskin yang bermasalah dengan hukum di tahun 2018. Tiap-tiap bantuan hukum nilainya sebesar Rp 5 juta dengan persyaratan tertentu. Namun kuota bantuan hukum dari Pemkot Semarang untuk membantu warga miskin yang bermasalah dengan hukum sudah habis. Pemkot Kota Semarang meminta advokat atau pengacara atau badan hukum pengacara di Semarang, untuk membantu warga miskin Semarang yang bermasalah dengan hukum secara gratis. Berdasarkan uraian di atas, penulis tertarik untuk membuat skripsi dengan judul "Pemenuhan Hak Atas Bantuan Hukum Dalam Perkara Pidana Bagi Masyarakat Miskin Kota Semarang"

Berdasarkan uraian tersebut diatas, maka permasalahan yang akan dibahas dalam penelitian ini adalah :

1. Bagaimana mekanisme pemberian bantuan hukum pidana bagi masyarakat miskin di Kota Semarang ?

2. Bagaimana pemenuhan hak atas bantuan hukum pidana bagi masyarakat kota Semarang ?

3. Apa saja faktor penghambat pemenuhan hak atas bantuan hukum pidana bagi masyarakat Kota Semarang ?

\section{Metode Penelitian}

Metode pendekatan yang digunakan dalam penelitian ini adalah pendekatan yuridis normatif, yaitu penelitian yang menekankan pada ilmu hukum tetapi di samping itu juga berusaha menelaah kaidah-kaidah 
hukum yang berlaku di dalam masyarakat. $^{3}$

Spesifikasi yang digunakan dalam penelitian ini adalah deskriptif analitis karena dari penelitian ini diharapkan dapat diperoleh gambaran yang jelas, rinci dan sistematis tentang objek yang diteliti. Metode pengumpulan data yang dilakukan adalah studi kepustakaan (library research), dan sebagai data penunjang dilakukan wawancara dengan pihak LBH Semarang dan Pemkot Semarang. Metode penyajian data dalam penelitian ini menggunakan metode deskriptif analitis yaitu menjelaskan dan menggambarkan apa adanya sesuai permasalahan yang diteliti atau datadata yang telah terkumpul disajikan dalam bentuk uraian. Metode analisis data yang digunakan dalam skripsi ini adalah metode analisis kualitatif yaitu analisa yang sifatnya non statistik atau non matematis.

\section{Hasil Dan Pembahasan}

1. Mekanisme Pemberian Bantuan Hukum Pidana bagi Masyarakat Miskin di Kota Semarang

Mekanisme pemberian bantuan hukum yang dilaksanakan oleh LBH Semarang tersebut sejalan dengan hasil penelitian di Bagian Hukum Sekretariat Pemerintah Kota Semarang. Berdasarkan hasil wawancara diketahui bahwa mekanisme pemberian bantuan hukum perkara pidana di Pmerintah Kota Semrang dilaksanakan berdasarkan Peraturan Daerah Kota Semarang Nomor 1 Tahun 2016 tentang Penyelenggaraan Bantuan Hukum

3 Ronny Hanitijo Soemitro, Metodologi Penelitian Hukum dan Jurimetri, (Jakarta : Ghalia Indonesia, 1985), halaman 106. dan berdasarkan Peraturan Walikota Semarang Nomor 131 Tahun 2016 tentang Petunjuk Pelaksanaan Peraturan Daeah Kota Semarang Nomor 16 Tahun 2016 tentang Penyelenggaraan Bantuan hukum. Adapun mengenai syarat dan tata cara adalah sebagai berikut: $^{4}$

a. Penduduk Kota Semarang dibuktikan dengan KTP dan warga miskin dibuktikan dengan kartu identitas miskin atau SKTM

b. Warga yang memerlukan bantuan hukum mengajukan permohonan tertulis dengan dilampiri persyaratan, dokumen yang berkaitan dengan perkara, surat kuasa (apabila yang mengajukan keluarga)

c. Maksimal dalam waktu 3 hari LBH atau organisasi masyarakat yang melaksanakan bantuan hukum harus menjawab permohonan bantuan hukum dari masyarakat apakah diterima atau ditolak.

d. Pemberian bantuan hukum berupa pendampingan dari mulai tahap penyidikan di kepolisian hingga persidangan di pengadilan bersifat inkrach selama kuasa pemberi bantuan hukum tidak dicabut oleh penerima bantuan hukum.

Semua masyarakat miskin Kota Semarang tanpa terkecuali yang membutuhkan bantuan hukum dapat meminta bantuan hukum kepada penyelenggara bantuan hukum yang sudah terkreditasi dan

4 Wawancara dengan Bapak Muchammad Chasani, Staf Bagian Hukum Sekretariat Daerah Pemerintah Kota Semarang, (Semarang, 22 Agustus 2019) 
Pemerintah Kota Semarang telah memfasilitasinya dengan memberikan anggaran untuk penyelesaian perkara.

\section{Pemenuhan Hak Atas Bantuan Hukum Pidana Bagi Masyarakat Kota Semarang}

Berdasarkan hasil penelitian di Pemkot Semarang, pemenuhan hak atas bantuan hukum pidana bagi masyarakat di Kota Semarang sudah dilaksanakan oleh Pemerintah Kota Semarang sejak tahun 2011 diawali dengan dasar Peraturan Walikota Semarang Nomor 10 Tahun 2010. ${ }^{5}$

Sebagaimana diatur dalam Pasal 16 Undang-Undang Nomor 11 Tahun 2012, penerima bantuan hukum berhak :

a. Mendapatkan bantuan hukum hingga masalah hukumnya selesai dan/atau perkaranya telah mempunyai kekuatan hukum tetap, selama penerima bantuan hukum yang bersangkutan tidak mencabut surat kuasa

b. Mendapatkan bantuan hukum sesuai dengan standar bantuan hukum dan/atau kode etik advokat

c. Mendapatkan informasi dan dokumen yang berkaitan dengan pelaksanaan pemberian bantuan hukum sesuai dengan ketentuan peraturan perundangundangan.

Pemenuhan hak bantuan hukum bagi masyarakat miskin di

5 Wawancara dengan Bapak Muchammad Chasani, Staf Bagian Hukum Sekretariat Daerah Pemerintah Kota Semarang, (Semarang, 22 Agustus 2019)
Kota Semarang telah dilaksanakan menggunakan dana APBD sesuai dengan ketentuan Pasal 23 Peraturan Daerah Nomor 1 Tahun 2016 yang menyatatakan bahwa pemerintah daerah wajib mengalokasikan dana penyelenggaraan bantuan hukum dalam Anggaran Pendapatan dan Belanja Daerah sesuai kemampuan keuangan daerah. Pada tahun 2019 Pemerintah Kota Semarang telah menganggarkan dana sebesar $\mathrm{Rp}$ 705.000.000,- untuk dialokasikan pada pemberian bantuan hukum. Dana tersebut sudah terealisasi dan sudah habis sejak bulan Juli 2019. ${ }^{6}$

Pemenuhan hak bantuan hukum pidana di Kota Semarang belum bisa dilaksanakan secara keseluruhan, mengingat terbatasnya anggaran biaya. Sebagaimana diketahui bahwa untuk anggaran biaya tahun 2019 sudah terserap habis sejak bulan Juli yang lalu. Hal ini mengakibatkan banyak permohonan bantuan hukum yang ditolak karena terbatasnya biaya. ${ }^{7}$

3. Faktor Penghambat Pemenuhan Hak Atas Bantuan Hukum Pidana Bagi Masyarakat Kota Semarang

Berdasarkan hasil penelitian diketahui terdapat faktor penghambat pemenuhan hak atas bantuan hukum pidana bagi masyarakat Kota Semarang yaitu :

\footnotetext{
6 Wawancara dengan Bapak Muchammad Chasani, Staf Bagian Hukum Sekretariat Daerah Pemerintah Kota Semarang, (Semarang, 22 Agustus 2019)

7 Wawancara dengan Bapak Muchammad Chasani, Staf Bagian Hukum Sekretariat Daerah Pemerintah Kota Semarang, (Semarang, 22 Agustus 2019)
} 
1) Faktor pendanaan

Pemerintah

Kota

Semarang

telah

menganggarkan dana

tersendiri untuk pembiayaan pemberian bantuan hukum bagi masyarakat miskin. Pembiayaan tersebut dibiayai oleh Anggaran Pendapatan Belanja Daerah (APBD) Kota Semarang. ${ }^{8}$

Sistem penganggaran APBD hanya bisa membiayai untuk tahun berjalan, sehingga untuk kasus yang diputus pada akhir bulan desember tidak bisa mendapatkan bantuan. Dalam hal ini solusinya adalah meminta LBH pelaksana bantuan hukum untuk meminta penundaan putusan agar diputus bulan Januari.

2) Faktor penegak hukum Pelaksanaan pemberian bantuan hukum perkara pidana melalui jalur litigasi akan berhadapan dengan aparat penegak hukum. Pada prakteknya terdapat kendala ketika kasus sudah sampai di tingkat kepolisian, karena aparat penegak hukum kurang maksimal dalam penanganan kasus. Kasus yang sudah masuk terkesan digantung dan tidak segera terselesaikan. ${ }^{9}$

Dalam sistem peradilan pidana Indonesia para

8 Wawancara dengan Bapak Muchammad Chasani, Staf Bagian Hukum Sekretariat Daerah Pemerintah Kota Semarang, (Semarang, 22 Agustus 2019)

9 Wawancara dengan Herdin Pardjoangan, Advokat LBH Semarang, (Semarang, 23 Agustus 2019). penegak hukum dengan fungsinya masing-masing, yaitu meliputi kepolisian, kejaksaan, pengadilan, lembaga pemasyaraatan. Kepolisian merupakan pintu gerbang bagi para pencari keadilan, karena sinilah segala sesuatu proses peradilan pidana dimulai. Lembaga kejaksaan sebagai lembaga yang bertugas melakukan penuntutan terhadap suatu tindak pidana. Pada Pasal 2 Undang-Undang Nomor 16 Tahun 2004 tentang Kejaksaan Republik Indonesia disebutkan bahwa kejaksaan adalah lembaga pemerintahan yang melaksanakan kekuasaan negara di bidang penuntutan serta kewenangan lain berdasarkan undang-undang. Pengadilan adalah pelaksanaan atau penerapan hukum terhadap suatu perkara dengan suatu putusan hakim yang bersifat melihat, putusan mana dapat beruap pemidanaan, pembebasan maupun pelepasan hukuman terhadap pelaku." 10

3) Faktor masyarakat

Hasil penelitian baik di LBH Semarang maupun di Bagian Hukum Setda Kota Semarang menyatakan bahwa tidak semua masyarakat mengetahui tentang adanya bantuan hukum secara cuma-

\footnotetext{
${ }^{10}$ Rusli Muhammad, Sistem Peradilan Pidana Indonesia (Dilengkapi dengan 4 UndangUndang di Bidang Sistem Peradilan Pidana, (Yogyakarta : UII Press, Yogyakarta, 2011), halaman 24.
} 
cuma bagi masyarakat dalam perkara pidana. Masyarakat masih banyak yang belum sadar hukum, sehingga ketika terlibat kasus dengan hukum banyak yang bersikap pasif dan hanya menerima tanpa ada upaya untuk mencari pendampingan hukum.

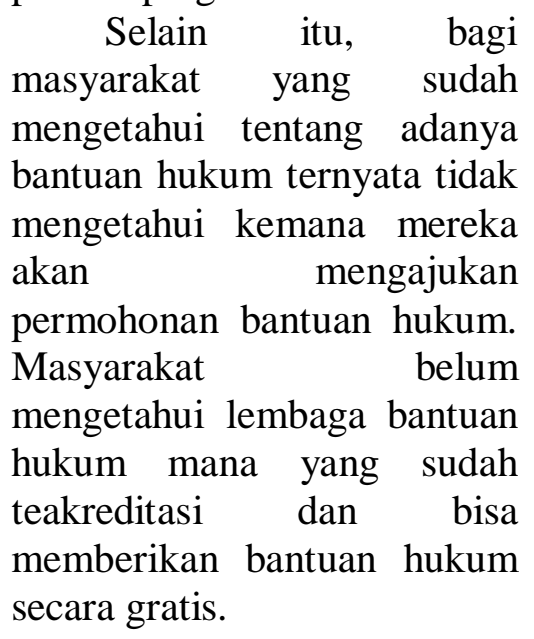

\section{Simpulan}

1. Mekanisme pemberian bantuan hukum pidana bagi masyarakat miskin di Kota Semarang telah sesuai dengan ketentuan perundang-undangan yang berlaku, yaitu pemohon mengajukan permohonan kepada pemberi bantuan hukum dengan melampirkan semua persyaratan yang telah ditentukan Pemberian bantuan hukum litigasi yaitu berupa pendampingan terhadap tersangka dari proses penyidikan sampai dengan putusan inkrah selama penerima bantuan hukum tidak mencabut surat kuasa. Sedangkan bantuan hukum non litigasi dilakukan dengan mediasi, negosiasi ataupun advokasi. Setelah pelaksanaan pendampingan hukum selesai, pemberi bantuan hukum dapat mengajukan permohonan pembayaran penggantian biaya kepada Pemerintah Kota Semarang.

2. Pemenuhan hak atas bantuan hukum pidana bagi masyarakat kota Semarang sejauh ini belum maksimal karena belum bisa dirasakan oleh seluruh lapisan masyarakat khususnya masyarakat miskin yang belum mengetahui akan adanya bantuan hukum gratis, dan kurangnya anggaran biaya yang ditetapkan dalam APBD.

3. Faktor penghambat pemenuhan hak atas bantuan hukum pidana bagi masyarakat Kota Semarang adalah faktor pendanaan yaitu keterbatasan anggaran biaya sehingga tidak bisa mengcover semua kasus yang masuk, faktor penegak hukum adanya sikap dari penegak hukum khususnya kepolisian yang terkesan menunda-nunda kasus sehingga proses peradilan pidana berjalan lama; dan faktor masyarakat yaitu kurangnya kesadaran hukum dari masyarakat serta ketidaktahuan masyarakat akan adanya pemberian bantuan hukum gratis bagi masyarakat miskin..

\section{Saran}

1. Hendaknya Pemerintah Kota Semarang menambah anggaran untuk pemberian bantuan hukum agar bisa mengcover semua kasus yang masuk sehingga pemberian bantuan hukum lebih optimal.

2. Perlu dilakukan upaya sosialisai terhadap masyarakat mengenai pemberian bantuan hukum bagi masyarakat miskin dan juga mengenai lembaga bantuan hukum 
yang sudah terakreditasi yang ada di Kota Semarang.

3. Bagi aparat penegak hukum hendaknya tidak menunda-nunda kasus yang sudah masuk di tingkat penyidikan agar proses pemberian bantuan hukum dapat berjalan efektif dan efisien

\section{Daftar Pustaka}

\section{Literatur}

Ronny Hanitijo Soemitro, Metodologi

Penelitian Hukum dan Jurimetri, Jakarta : Ghalia Indonesia, 1985.

Rusli Muhammad, Sistem Peradilan Pidana Indonesia, UII Press, Yogyakarta, 2011.

\section{Peraturan Perundang-Undangan}

Kitab Undang-Undang Hukum Acara

Pidana

Undang-Undang Republik Indonesia Nomor 16 Tahun 2011 tentang Bantuan Hukum

Peraturan Daerah Provinsi Jawa Tengah Nomor 7 Tahun 2014 Tentang Bantuan Hukum Kepada Masyarakat Miskin

Peraturan Daerah Kota Semarang Nomor 1 Tahun 2016 tentang Penyelenggaraan Bantuan Hukum.

\section{Website}

Pemkot Semarang Hanya Bisa sekali Beri Bantuan Hukum kepada Warga Miskin, (http://jateng.tribunnews.com, diakses 20 September 2018). 